\title{
Erratum to: Solar Intranetwork Magnetic Elements: Evolution and Lifetime
}

\author{
G.P. Zhou · J.X. Wang • C.L. Jin
}

Published online: 20 November 2010

(C) Springer Science+Business Media B.V. 2010

\section{Erratum to: Solar Phys}

DOI 10.1007/s11207-010-9641-1

Within the abstract there is an error in the following sentence:

The lifetime of IN elements is correlated closely with their flux.

The correct sentence is:

The lifetime of IN elements is correlated weakly with their flux.

The online version of the original article can be found under doi:10.1007/s11207-010-9641-1.

G.P. Zhou $(\bowtie) \cdot$ J.X. Wang $\cdot$ C.L. Jin

Key Laboratory of Solar Activity, National Astronomical Observatories, Chinese Academy of Sciences, Beijing 100012, China

e-mail: gpzhou@ourstar.bao.ac.cn

J.X. Wang

e-mail: wangjx@bao.ac.cn

C.L. Jin

e-mail: jinchunlan@bao.ac.cn 